\title{
Arthropod segments and segmentation - lessons from myriapods, and open questions
}

\author{
A. MINELLI \\ Alessandro Minelli, University of Padova, Department of Biology, Via U. Bassi 58 B, I 35131 \\ Padova, Italy.E-mail: alessandro.minelli@unipd.it
}

\begin{abstract}
The current understanding of the segmental organization of myriapods is dramatically different from the traditional views, due both to fresh research on a number of myriapod species and to progress in comparative developmental biology at large. In the late eighties, the emerging paradigm of ecdysozoan affinities of arthropods prompted a revisitation of the concept of the segment as an archetypical body unit. Fresh approaches to myriapod comparative morphology and pioneering studies on the developmental genetics of segmentation in Strigamia maritima, Lithobius atkinsoni and Glomeris marginata contributed to the definitive abandonment of the Articulata hypothesis and suggested a reformulation of the segment concept as the product of a functional integration between a number of distinctly repeated serial units, e.g. neuromeres, tergites, sternites. In the light of this refreshed interpretation of myriapod segmental architecture, we must reject the naïve views that (a) segment production is necessarily prior to segment patterning, (b) serial features evolve from polymerous and poorly patterned to oligomerous and strongly patterned series (Williston's law), and (c) the divide between embryonic and post-embryonic development is necessarily a major turning point in morphogenetic processes. Open questions remain, e.g. to which extent the production of serial structures along the main body axis of myriapods is multiplicative rather than sequential.
\end{abstract}

Keywords. Anamorphosis, developmental genetics, epimorphosis, saltational evolution, Williston's rule.

\section{ARTHROPOD SEGMENTS - THE TRADITIONAL VIEW}

$\mathrm{U}$ $\mathrm{p}$ to the last quarter of the XX century, the segmented nature of the main body axis of the Arthropoda was generally accepted as well understood, except perhaps for specific problems of homology, e.g. the debated nature of the terminal body units, customarily known as the acron and the telson and mostly regarded as nonsegmental.

According to the different perspectives from which it was considered, the segment was regarded as an archetypical module of arthropod body architecture, as a fundamental building block in development and also as an evolutionarily conserved trait shared by all Articulata, i.e. annelids, onychophorans, tardigrades and arthropods.
In this context, myriapods represented a study object of choice, for a number of reasons. First, because of the conspicuous articulation of their long trunk into serial units with numbers often exceeding those of all other extant arthropods (a female specimen of Illacme plenipes Cook \& Loomis, 1928 with 192 (diplo)segments and 750 legs, thus approaching the target of the thousand legs according to which these animals are named in many languages, was described by Cook \& Loomis 1928). Second, because of the modest degree of regional specialization within the trunk, a condition regarded as more primitive than e.g. the more extensive patterning (thorax and abdomen, at least) found in the hexapods. Third, because of the diversity of segmental patterns occurring in this lineage, including features not found in any other arthropod clade (Fusco \& Minelli 2013, Minelli \& Fusco 2013). An overview of these features follows here; the taxonomic arrangement of the myriapod taxa discussed in this article is given in Table 1. 
Table 1. Taxonomic arrangement of the myriapod taxa discussed in the text.

Chilopoda

Scutigeromorpha: Scutigera

Lithobiomorpha: Lithobius atkinsoni Bollman, 1887

Craterostigmomorpha

Scolopendromorpha: Scolopendropsis bahiensis (Brandt, 1841), Sc. duplicata Chagas-Junior, Edgecombe \& Minelli, 2008

Geophilomorpha

Placodesmata

Mecistocephalidae: Mecistocephalus diversisternus (Silvestri, 1919), M. japonicus Meinert, 1886, M. microporus Haase, 1887

Adesmata

Himantariidae: Himantarium gabrielis (Linnaeus, 1767), Stigmatogaster subterraneus (Shaw, 1789)

Oryidae: Orphnaeus heteropodus Lawrence, 1963

Linotaeniidae: Strigamia maritima (Leach, 1817)

Diplopoda

Geophilidae: Clinopodes flavidus C.L. Koch, 1847

Penicillata

Polyxenida: Polyxenus lagurus (Linnaeus, 1758)

Chilognatha

Pentazonia

Limacomorpha

Glomeridesmida

Oniscomorpha

Sphaerotheriida

Glomerida: Glomeris marginata (Villers, 1789)

Helminthomorpha

Colobognatha

Platydesmida: Illacme plenipes Cook \& Loomis, 1928

Siphonocryptida

Eugnatha

Merocheta

Polydesmida: Devillea, Dobrodesmus mirabilis Shear, Ferreira \& Iniesta, 2016, Nannaria conservata Chamberlin, 1940, Polydesmus angustus Latzel, 1884, P. complanatus (Linnaeus, 1761)

Nematophora

Chordeumatida

Callipodida

Stemmiulida

Juliformia

Julida: Ommatoiulus moreleti (Lucas, 1860), Pachyiulus flavipes (C.L. Koch, 1847)

Spirostreptida

Spirobolida

incertae sedis: Siphoniulida

Pauropoda

Symphyla 
Dorsoventral mismatch. - The units serially repeated along the trunk of myriapods are mostly very different from the textbook idealized segment with dorsal and ventral sclerites (tergites and sternites, respectively) in 1 to 1 relationship, together with one pair of articulated limbs and perhaps one or more additional sclerites (pleurites) in lateral position between tergite and sternite. The most familiar example of departure from this scheme is found in millipedes (Diplopoda), the trunk of which next to a legless collum and (generally) three units with one pair of legs each - features a more or less numerous series of units with two pairs of legs each. According to the group, the serial units corresponding to sets of two pairs of legs each are either restricted to the dorsal sclerites, or extended to also involve part or all of the lateral and ventral sclerites. In the Pentazonia, tergites and pleurites are not fused and the sternites are very small (Glomeridesmidae) or, more frequently, absent. Within the Helminthomorpha, tergites, pleurites and sternites (to which the stigmatic plates are attached) are generally separate only in the Colobognatha, while in the Eugnatha these units are more or less extensively fused. In the Chordeumatida, Callipodida and Stemmiulida, the trunk is formed by 'rings' in which sterna+stigmatic plates do not fuse with the pleuroterga (tergum+pleura), but in the Juliformia, Polydesmida and Siphoniulida all segmental sclerites are fused to form complete rings. This distinction between ring and 'ring' is in agreement with the recent overview of millipede taxonomy by Enghoff et al. (2015).

An extensive mismatch between dorsal and ventral segmentation is observed also in pauropods and in symphylans. Within the Chilopoda, the Scutigeromorpha have 15 leg-bearing segments (LBS), and the corresponding sternites, but only seven tergites, while the Craterostigmomorpha, also with 15 LBS, have 21 tergites.

Forbidden numbers. - In centipedes, specimens with an even number of LBS are limited to some early post-embryonic stages in species belonging to the hemianamorphic clades, e.g. Lithobius and Scutigera, but only odd number of LBS - between 15 and 191 - are found in adult
Chilopoda (e.g., Minelli \& Bortoletto 1988, Arthur \& Farrow 1999), including those with segmentation defects, except for a 'monster' specimen of Stigmatogaster subterraneus (Shaw, 1789 ) with 80 LBS, described and discussed in Leśniewska et al. (2009).

Number fixed in major lineages. - In many myriapod clades, segment number is very strictly fixed, in others however it is more or less extensively variable (see table in Minelli \& Fusco 2013). For example, the number of LBS is 15 in all adult centipedes belonging to the Scutigeromorpha, Lithobiomorpha and Craterostigmomorpha, but it varies between 27 and 191 (odd numbers only!) in Geophilomorpha.

Of interest, in exploring the evolvability of segment number as a possible cue to discovering the underlying developmental mechanisms, are the rare exceptions recorded in clades otherwise remarkable for stability in segment number. One example are the scolopendromorph centipedes, with a majority of species having 21 pairs of legs, a sizeable minority 23 , the only two exceptions (to which we will return later) being Scolopendropsis bahiensis (Brandt, 1841), in which individuals with 21 LBS occur alongside others with 23 (Schileyko 2006), and the closely related Sc. duplicata Chagas-Junior, Edgecombe \& Minelli, 2008, with individuals of both sexes with either 39 or 43 LBS (Chagas-Júnior et al. 2008).

Differences between the sexes. - The number of segments is often the same in both sexes, but with major exceptions. The sex with higher segment number is either the male or the female, according to the group. In glomerid and sphaerotheriid millipedes males have two tergites more than the conspecific females, while in the other myriapod clades with sexually dimorphic segment number, males have less numerous segments than the conspecific females: the difference is two tergites in some species of Polydesmida, two or more tergites in many millipedes and two or more LBS in geophilomorph centipedes except for the Mecistocephalidae. In a number of geophilomorphs belonging to several independent clades in which there is also intraspecific variation affecting both sexes, 
the modal difference is equal or close to a multiple of two, up to 16 segments (Minelli \& Bortoletto 1988, Berto et al. 1997). In Orphnaeus heteropodus Lawrence, 1963 (Oryidae) the females have been described as possessing about twice as many trunk segments as the males (Lawrence 1963), but the original description is inaccurate, as Lawrence (1963) gave the following counts for the specimens on which he described the species: 57, 60 and 65 LBS in the three males, 119 and 120 in the two females; both 60 and 120 are even numbers, thus very unlikely, given the universality of odd number of LBS in the Chilopoda.

Intraspecific variation. - Within the Chilopoda, besides the two species of Scolopendropsis cited above, there is within-sex intraspecific variation in the number of trunk segments in most of the Geophilomorpha except for the vast majority of the Mecistocephalidae. Within the latter, however, this condition has evolved at least three times; as expected, variation has been recorded in the mecistocephalid species with the highest total segment number: 57 or 59 LBS in Mecistocephalus diversisternus (Silvestri, 1919), 63 or 65 in $M$. japonicus Meinert, 1886, and between 93 and 101 in M. microporus Haase, 1887 (Bonato et al. 2003, Uliana et al. 2007). Within the Adesmata, the clade of geophilomorphs sister to the Mecistocephalidae, the range of variation within a species varies between 2 LBS and more than 80 (Himantarium gabrielis (Linnaeus, 1767) (Minelli et al. 1984, Minelli \& Bortoletto 1988). Within the Diplopoda, intraspecific variation is universal in the euanamorphic clades, but has been additionally recorded in teloanamorphic (several Callipodida) and hemianamorphic species (one species of Glomeridesmida and several Spirostreptida and Spirobolida, in the latter with intraspecific variation in a range up to 10 rings) (Enghoff et al. 1993).

Occasional instability in segment number has been occasionally recorded in otherwise segment-invariant species such as Polydesmus complanatus (Linnaeus, 1761) and P. angustus Latzel, 1884 in which occasional supernumerary molts have been found to release individuals with one extra leg-bearing ring (Verhoeff 1916, 1928, David \& Geoffroy 2011).

Patterns of segment addition during postembryonic development. - In a pioneering paper on myriapod reproduction and development, Fabre (1855) suggested a 'law of anamorphosis' according to which all apodous rings of a given pre-adult stage will bear two pairs of legs each in the following developmental stage. Fabre documented this regularity in Polydesmus complanatus. Subsequent authors demonstrated that this 'law' is not restricted to polydesmidans, but also applies to other clades, but it is not universal for millipedes: indeed, it is limited to two major clades, the Merocheta (Polydesmida) and the Juliformia (Julida + Spirobolida + Spirostreptida) (Enghoff et al. 1993). There is no consistent correlation between the kind of anamorphosis (i.e., hemi-, telo- and euanamorphosis) and a segment addition agreeing or not with Fabre's rule.

Lack of segment regeneration. - In myriapods, and in arthropods at large, regeneration is limited to the appendages. The process is well documented in Scutigeromorpha and Lithobiomorpha (both legs and antennae), less so in Scolopendromorpha, where it is possibly limited to the last pair of legs and the antennae; no reliable example of regeneration of appendages is available for the Geophilomorpha (Minelli et al. 2000). In millipedes, evidence of regeneration is also restricted to the antennae, where autotomy may occur between articles II and III (Polydesmus angustus; Petit 1974) or between III and IV (Polyxenus lagurus (Linnaeus, 1758); Nguyen Duy-Jacquemin 1972), and the legs (Petit 1973), but experimental evidence is available for very few species only. One might expect that myriapods (and other arthropods) with anamorphic development would regenerate segments posteriorly, but this is not the case. This shows that the posterior growth zone of anamorphic or hemianamorphic myriapods is not a unpatterned blastema, but rather an irreplaceable organizing region. 


\section{NEW FRAMEWORKS AND NEW EVIDENCE}

Current appreciation of the nature and evolution of segmentation in myriapods is largely the result of a renewed intellectual framework involving phylogenetics, macroevolution and developmental biology.

\section{The phylogenetic context}

Until the late ' 80 s of the past century, arthropods were generally regarded as closely related to the annelids, the other major phylum of overtly segmented animals. In this context, myriapods, with their worm-like habitus and the modest degree of regional patterning along the trunk, seemed to represent a natural midway step along a morphocline beginning with homonomously segmented and limbless annelids and eventually ending in heteronomous segmented arthropods with body articulated in three tagmata (e.g., the head, thorax and abdomen of insects) and provided with segmental pairs of limbs with specializations parallel to the anatomical and functional differentiation of body regions. To some extent, the old notion of the Articulata, introduced by Cuvier (1816) for this embranchement of segmented animals, seemed still acceptable and even suitable as phylogenetic background for a reconstruction of the evolution of the evidence emerging from comparative developmental genetics. But a close relationship between Arthropoda and Annelida is not supported by molecular evidence. Instead, one of the most important results of the earliest efforts in molecular phylogenetics at the level of the relationships among the major clades of metazoans was the demonstration of the close affinities between the arthropods and the other molting animals (Aguinaldo et al. 1997). Even earlier, a phylogenetic analysis based on a large dataset of morphological and embryological data (Eernisse et al. 1992) had also failed to provide support for the Articulata. The Articulata hypothesis was rapidly abandoned, although with some resistance, in favor of the Ecdysozoa hypothesis (for arthropods) and the Spiralia and Lophotrochozoa hypotheses (for annelids). The phylogenetic background against which to reconstruct the origin and evolution of segmentation in Arthropoda must therefore accept their closer relationships to the Nematoda etc. rather than to the Annelida.

Interestingly, myriapods and their segments have played a role in stimulating a revisitation of the phylogenetic relationships between the arthropods and other metazoan phyla. In discussing the potential implications of models of segmentation suggested by the distribution of segment numbers in several myriapod clades, Minelli \& Bortoletto (1988, p. 340) remarked that arthropod and annelid segments might not be homologous, as generally taken for granted, while "In annelids, segments are primarily mesodermal units arising in serial sequence by steps punctuated by mitotic cycles, whereas in Atelocerata (possibly in all arthropods) they are primarily ectodermal units, not arising in sequence, but by iterative doubling of biochemical markings laid down independently from mitotic cycles." In this sentence, two points have not resisted the progress of knowledge in the following thirty years, namely the Atelocerata (myriapods+hexapods) hypothesis, which has been rejected in favor of a closer alliance between crustaceans and hexapods, and the suggestion that double-segment periodicity might be universal among arthropods, but this does not shake the main point, eventually accepted by most zoologists today.

The general question, how many times segmentation might have emerged among metazoans, is still open to discussion (e.g., Davis \& Patel 1999, Seaver 2003, Minelli \& Fusco 2004, De Robertis 2008, Tautz 2004, Couso 2009, Chipman 2010, 2019, Hannibal \& Patel 2013).

\section{Macroevolutionary scenarios}

A naïve approach to evolutionary trends in animal (and plant) clades whose representatives feature serial structures in a diversity of numbers and degrees of specialization may suggest, as a rule, a progressive reduction in the number of units and a corresponding increase in their specialization. In arthropods, and in myriapods 
particularly, this would translate into a trend from a higher to a lower number of segments and from a less patterned to a more extensively patterned trunk. This corresponds to the socalled Williston's rule (e.g., Saunders \& Ho 1984). This putative macroevolutionary principle, however, often fails to withstand phylogenetic analysis (Minelli 2003). Opposite trends, in fact, prevail among myriapods. In Enghoff's (1990) reconstruction, there are no more than 21 body segments in the ground-plan of chilognathan millipedes, while among the geophilomorph centipedes there is no consistent trend in either increase of decrease of segment number (Bonato et al. 2014) or in complexity (local patterning) of the trunk (Berto et al. 1997).

\section{New taxa and phylogenetic analysis}

Our current appreciation of ontogeny and evolution of the segmental organization of myriapod body has benefitted from the often revised and eventually stabilized reconstruction of the phylogenetic relationships among the major clades of Chilopoda and Diplopoda (e.g., Shear \& Edgecombe 2010, Edgecombe 2011, 2015, Fernández et al. 2018) as well as by phylogenetic analyses of smaller clades, e.g. the Mecistocephalidae, within which both decrease and increase in segment number have been revealed, including whole-trunk duplication accompanied by release of intraspecific variation in segment number (Bonato et al. 2001, 2003). Moreover, as discussed below, of critical importance has been the discovery of species with segment number very different from the condition in all other species in their clade, namely the scolopendromorph centipede Scolopendropsis duplicata (Chagas et al. 2008) and the polydesmidan millipede Dobrodesmus mirabilis Shear, Ferreira \& Iniesta, 2016 (Shear et al. 2016).

\section{Segment production, before and after hatching}

The only myriapod with intrapopulation variation in adult segment number for which experimental studies on the possible causes of this variation are available is the geophilomorph centipede Strigamia maritima (Leach, 1817). In this species, segment number is slightly influenced by the temperature to which the embryo is exposed (Vedel et al. 2008), especially during blastoderm formation and before, or very shortly after the onset of segmentation (Vedel et al. 2010). A genetic component, however, seems to be also present (Vedel et al. 2009).

Precious efforts, aided by progress in microscopy and imaging technology, have been put into refreshing descriptive embryology. Of this production, which has revealed important gaps and errors in the old literature on this subject, I will briefly summarize here the work of Brena \& Akam $(2012,2013)$ and Brena (2014) on S. maritima.

In the embryo of this species, most trunk segments take shape as morphogenetic units marked by the regularly spaced expression of segmentation genes with periodicity equivalent to two future segments (Chipman et al. 2004a). However, the most posterior segments are laid down as single segments, rather than as doublesegment units, and the process is associated with active cell proliferation, a feature usually characteristic of post-embryonic elongation.

Unexpectedly, a rudimentary leftover of anamorphosis is present in this centipede, as the genital segments are added after hatching, at which time, additionally, the prospective last leg-bearing segment is limbless and in some individuals the external delineation of this segment is only manifest at the beginning of the post-embryonic life. Previous to this study, posthatching addition of a few segments in some geophilomorph species was suggested by Archey (1936) and Misioch (1978), but this had been discounted (Prunescu \& Capuse 1971, Minelli 1985, Horneland \& Meidell 1986) as based on unconvincing evidence.

As noted by Brena (2013), these newly discovered features of segment production in Strigamia suggest that, in this clade at least, the pre- vs. post-hatching divide is not a clear-cut one, something already questioned by Minelli $e t$ 
al. (2006). Nor is this divide strictly comparable, even among close relatives: at stage I most millipedes have three pairs of legs, but several exceptions have been recorded, apparently restricted to individual species, e.g. 27 pairs in Pachyiulus flavipes (C.L. Koch, 1847) (Dirsh 1937), whereas in all other members of the Julida for which the number of LBS at stage $\mathrm{I}$ is known, this number is always three.

\section{Modes of segment production}

In his excellent review of myriapod evodevo, Brena (2015) remarked that no general model is available at this time to explain the spatial and temporal patterns of segment production in myriapods. Basically, segments in myriapod embryos differentiate in anteroposterior sequence from a posterior segment addition zone, but the latter is probably better described as a segmental organizer rather than as a segment generator (Fusco 2005).

A problem with a strictly sequential production of segments from a posterior (subterminal) part of the body is the nearly absolute precision required to generate segmented animals with a total segment number fixed at the level of species and also conserved throughout major clades. Based on the unlikely existence of a 'counting device' of such precision, Maynard Smith (1960) suggested that the constancy in segment number peculiar to many myriapod clades could be tentatively explained as the result of a different process of segment production. Segmentation would thus be obtained in two steps: first, the production (perhaps in the ordinary, progressive way) of a quite small number of primary segments, followed by one or more rounds of duplication, that is, splitting of each primary segment into two secondary (or tertiary etc.) segments. Controlling both steps (the production of a small number of primary segments and their subsequent duplication) and thus escaping variation in segment number would be much easier and thus more likely than an error-free sequential process producing high but also fixed numbers of units, one after the other. According to Minelli \& Bortoletto (1988), a multiplicative process of segmentation would also explain several features of the distribution of segment numbers in myriapods other than the frequent stability of high segment numbers, in particular the idiosyncratic lack of centipedes with even number of LBS and some segment number distributions in selected clades of Geophilomorpha, where relative frequency maxima are spaced by intervals of $2^{\mathrm{n}}$ units. This model has been further developed in subsequent papers by this author (Minelli 2000, 2001). A few years before, spatial patterns of gene expression with 2 -segment periodicity were discovered in Drosophila (Nüsslein-Volhard \& Wieschaus 1980) and both their significance as a possible step in body (or at least trunk) segmentation and their occurrence in different arthropod clades, myriapods included, has been targeted by developmental geneticists.

The multiple-duplication model performs much better than alternative models of arthropod segmentation in respect to two critical predictions.

The first prediction is about the evolvability of segment number in epimorphic centipedes and in millipede clades in which segment number is not fixed. If the binary splitting of primary segments hypothesized under the multiplicative model of segmentation is occasionally repeated one extra time, individuals will be produced with a roughly duplicated number of segments, and no intermediate will be found between specimens with the original number and those expressing the duplication. This would be an example of 'saltational' evolution. This is a sensible explanation for the occurrence, in Scolopendromorpha, of the two closely related species mentioned above, one of which (Scolopendropsis duplicata) has a segment number approximately double compared to the other ( $S c$. bahiensis) (Minelli et al. 2009). A parallel case of 'whole-trunk duplication' is represented by a recently described representative of the teloanamorphic millipedes. Uniquely among the Polydesmida, in the adult males of Dobrodesmus mirabilis there are 39 rings (Shear et al. 2016), whereas the number of rings in the vast majority of species in the same order is 19 , the remaining ones having between 17 and 21 rings, except for some species in the genus 
Devillea, with up to 28 rings (Enghoff et al. 1993, David \& Geoffroy 2011).

A second kind of prediction is about multisegmental patterns due to late effects of positional markers expressed much earlier in development. Invoking regularities in the postembryonic segment addition is arguably sensible as an explanation for the serial color patterns described by Enghoff (2011) in several species belonging to Spirobolida, Spirostreptida, Platydesmida, Siphonocryptida and Chordeumatida, consisting of units, each of which extends over several rings. In the majority of cases, the elements of these patterns correlate with the successive batches of segments added with subsequent molts, as expected in the light of the so-called 'law of anamorphosis' (Fabre 1855) mentioned above. However, rather than agreeing with the pattern of stepwise addition of segments at the posterior end of the trunk, the distribution of other multisegmental patterns may mirror instead an early expression of positional markers. This is likely the case in the julid millipede with ectopic extra pairs of gonopods described by Akkari et al. (2014). In this male specimen of Ommatoiulus moreleti (Lucas, 1860) there are eight pairs of gonopods: the usual two pairs representing the appendages of ring 7 (positionally homologous to leg-pairs 8 and 9), plus six extra pairs of gonopods replacing the walking legs of rings 8,15 and 16 (positionally homologous to leg-pairs 10-11, 24-25 and 26-27, respectively). Thus, in this specimen there are two distinct sets of four pairs of gonopods each, the anterior one corresponding to leg-pairs $8-11$, the posterior one to legpairs 24-27. The fact that the posterior set reiterates the anterior one after exactly 16 leg positions along the main body axis suggests that a body section corresponding to eight rings (16 leg-pairs) might be a structural module deriving from 4 cycles of regular binary splitting of an embryonic 'primary segment'. As to the discontinuous distribution of gonopod pairs in the teratological specimen, let's consider that, very likely, in male helminthomorph millipedes generally, the positions where walking legs will metamorphose into gonopods are marked early, during embryonic development, by the localized expression of a 'position marking gene', perhaps the Hox gene Abdominal-B (Drago et al. 2008). This may explain the distribution of the extra gonopods in the homeotic specimen, if the molecular marker 'interpreted' post-embryonically as fixing the position for the walking legto-gonopod metamorphosis was present in a primary trunk segment before its eventual splitting into secondary segments (mechanistic details are given in the original paper). But this explanation is only compatible with a multiplicative model of segmentation, whereas the alternative model does not offer any plausible explanation for the observed pattern.

Also in favor of a multiplicative, rather than strictly serial model of segmentation is the segmental anomaly described by Shelley (1975) in a male of Nannaria conservata Chamberlin, 1940. This polydesmidan features three pairs of gonopods: the normal ones, corresponding to leg-pair 8, plus two ectopic pairs, in the place of leg-pairs 4 and 12, respectively. In other words, the three gonopod pairs in this specimen are spaced by two intervals of 4 units (leg-pairs) each. This has been interpreted by Akkari et al. (2014) as suggesting a degree of segment multiplication lower than in $O$. moreletii, in agreement with a total number of segments much lower in a typical polydesmidan than in an average julid.

\section{Developmental genetics}

The single most important field that has opened new vistas in understanding arthropod (and myriapod) segmentation is developmental genetics, despite the fact that up to now these studies have been limited to three species only, the pill millipede Glomeris marginata (Villers, 1789) and two centipedes, Lithobius atkinsoni Bollman, 1887 and Strigamia maritima.

Several sets of genes are involved in the segmentation of the arthropod germ-band, in particular the pair-rule genes, expressed in the embryo in domains often corresponding to two (definitive) segments of the animal, hence the name, and the segment polarity genes, by the expression of which segment boundaries are generated. Most of the genes of these two 
classes, first discovered in Drosophila, are present in arthropods generally, myriapods included, and are similarly involved in segmentation, although the precise mechanics of the process may differ. Divergence is more extensive in gene expression at the earlier embryonic stages, whereas the involvement of segment polarity genes (especially engrailed and wingless) in generating segmental boundaries has been found in all arthropods studied thus far (Peel 2004, Peel et al. 2005, Chipman 2008).

Pair-rule genes and their expression. - Because of their widespread bisegmental patterns of expression, pair-rule genes have been most closely targeted in the study of myriapod developmental genetics. In Drosophila, some of these genes (even-skipped, oddskipped, hairy and runt) are initially expressed in a twosegment periodicity, but the large transversal bands in which they are expressed split subsequently to give a pattern with single-segment periodicity on the segmented germ band. The circumstance that only odd numbers of LBS between 15 and 191 - are found in adult Chilopoda suggests that their germ band also undergoes a stage with double segment periodicity (Chipman et al. 2004a). Evidence of such a stage was not been recorded in the earliest studies on developmental genetics of centipedes (Hughes and Kaufman 2002, Kettle et al. 2003, Chipman et al. 2004b), but was eventually demonstrated for two genes in the embryo of Strigamia maritima (Chipman et al. 2004a). As recently noted by Clark et al. (2019), it is still uncertain where and how many times, in arthropod evolution, the bisegmental pattern of expression of pair-rule genes evolved.

As described in Drosophila and insects generally, in myriapods there are both early- and late-activated pair-rule genes, but the relative timing of expression of some genes of the first set is not the same as in insects (Green \& Akam 2013). Nevertheless, in both Strigamia (Janssen et al. 2011b, 2012) and Glomeris (Green \& Akam 2013), these genes are expressed in stripes preceding discernible morphological segmentation, a pattern suggesting their likely role in segment patterning (Brena 2015).
The stripes of expression of the segmentpolarity genes emerge at the anterior margin of the segment addition zone (Clark et al. 2019), progressively specified by the regularly periodic waves of expression of the primary pair-rule genes hairy, eve, runt and odd. This behavior, observed - among myriapods - both in Glomeris (Janssen et al. 2011) and in Strigamia (Green \& Akam 2013), has been described as a segmentation clock (Clark et al. 2019). In Strigamia, this periodic expression gives rise to stripes corresponding to all segments starting from the mandibular one (Brena \& Akam 2013). In myriapods (and in arthropods in general) the anterior part of the body possibly becomes segmented through a different mechanism (Brena 2015).

Segmentation vs. germ-band elongation. Remarkable is the apparent independence, in Strigamia at least (Brena \& Akam 2013, Brena 2015, Clark et al. 2019), of the early patterning process from germ-band formation and axis elongation, two processes usually considered intrinsically interconnected in arthropods (Sander 1976).

Ectoderm vs. mesoderm. - The early dynamic patterning process of the primary pair-rule genes has been shown in Strigamia to be specifically ectodermal (Green \& Akam 2013), as long ago tentatively suggested by Minelli \& Bortoletto (1988), who first pointed to this property as possibly differentiating arthropod segmentation from segmentation in annelids, where this process is primarily a mesodermal affair.

Pair rule gene expression in (hemi)anamorphic myriapods. - For centipedes other than Strigamia, the only available information about the developmental genetics of segmentation is Hughes \& Kaufman's (2002) study on the expression patterns of three segmentation genes (even-skipped, engrailed, and wingless) in Lithobius atkinsoni. In this centipede, the expression of even-skipped is apparently segmental (unlike the seven bisegmental stripes observed in the embryonic germ-band of Drosophila) and possibly limited to a part of the 
trunk rather than extending over its total length. It remains to be proved if this behavior specifically correlates with the hemianamorphic, rather than epimorphic, schedule of segment production in Lithobius.

Glomeris: gene expression and dorsoventral mismatch. - In Glomeris marginata, the study of the spatial and temporal patterns of expression of homologues of the genes known to be involved in the segmentation process in Drosophila and other arthropods have been targeted to address the developmental origin of the problematic serial units of the millipede trunk. Previous to the advent of developmental genetics, the obvious mismatch between the dorsal and ventral aspects of trunk segmentation in millipedes had been already interpreted as suggestive of independence between the developmental processes producing the dorsal vs. ventral serial units of the millipede body. Some arguments from comparative morphology were offered by Enghoff et al. (1993), e.g. the fact that in Glomerida sternites and leg-pairs differentiate at a pace other than the production of new tergites; the addition of leg-pairs in Glomeridesmus continuing even after the production of the last tergite, and the lack of correspondence, across the developmental stadia of platydesmids, between the number of tergites and the number of sternites and leg-pairs. In Glomeris marginata, several segmentation genes, the segment polarity genes especially, although homologous to those of the other arthropods, are expressed according to divergent patterns. For example, in G. marginata, wingless is expressed ventrally, but not dorsally; engrailed, hedgehog, cubitus-interruptus and patched are expressed both dorsally and ventrally, but the dorsal pattern of expression suggests that it is not involved in segmentation (Janssen et al. 2004, Damen et al. 2009). Most important, the spatial and temporal patterns of gene expression suggest that in Glomeris dorsal and ventral segmentation are uncoupled (Janssen et al. 2006a). Moreover, the boundaries between embryonic segments do not correspond to those between neighboring tergites (Janssen et al. 2006b). A bisegmental pattern of expression is observed in the blastoderm of Glomeris for pairberry and other pair rule gene orthologues (Janssen et al. 2012). These stripes split subsequently in two, as observed for the primary expression stripes of pair-rule genes in other arthropods, but this pattern does not correspond to either the ventral or dorsal segmental units of the millipede.

\section{CONCLUSIONS}

In the light of the observational and experimental evidence gathered in the last decades and the steadily revised interpretation of the diverse pieces of information, both old and new, available today, the most sensible starting point for an overall evaluation of our current understanding of segmentation in arthropods, and in myriapods specifically, is Hannibal \& Patel's (2013, p. 8) statement, that "more than two millennia of studying segmentation in animals have failed to produce a definition of segmentation that is applicable in even a majority of cases. Moreover, discussions on segmentation are often reduced to debates over the definition of segmentation and whether the animal or system described is actually segmented, rather than to debates over the developmental mechanisms and evolutionary processes."

Some provisional conclusions, however, can be offered:

The old notion, that the body of myriapods (and arthropods generally) is made of segments must be replaced with the notion that the body of these animals features a multiplicity of serially repeated units, partly but not necessarily or universally integrated into blocks approximating conventional textbook segments (Budd 2001). The trunk of a myriapod certainly exhibits segmental patterns, but is not made of segments (Fusco 2005, 2008).

Rather than resulting from the regular addition of 'preformed' segmental building blocks, the whole trunk - in centipedes at least appears to be the 'primary given' eventually subdivided into units of more or less strictly fixed number. For example, in the geophilomorph Clinopodes flavidus C.L. Koch, 1847, among the adults of the same sex belonging to 
the same population, total body length is independent from the number of segments, the latter being in inverse relationship to the average length of segments in the individual (Berto et al. 1997, Minelli et al. 2010; but see Hayden et al. 2012 for contrasting evidence in Strigamia maritima).

As far as the number and patterning of segments is concerned, the prevailing macroevolutionary trend in myriapods does not follow Williston's rule.

Kind and degree of integration among the different series of periodically arranged units, e.g. tergites, sternites and leg-pairs are not simply to be read in terms of function (locomotion, especially), but also in terms of mechanisms of segment production and patterning and especially of heterochronic shifts among the different processes involved.

The divide separating embryonic from postembryonic development and, as a consequence, the contrast of anamorphic vs. epimorphic developmental schedules are not necessarily solid, as traditionally accepted.

Bisegmental patterns of gene expression in the early embryo, following by splitting of the corresponding stripes into secondary, onesegment stripes, are likely more widespread, among arthropods in general and myriapods in particular, than accepted some years ago. It is possible that a multiplicative process of segmentation has evolved, in different myriapod lineages, by iteration of this mechanism of primary stripe splitting.

Many open questions remain, e.g. to what extent the production of serial structures along the main body axis of myriapods is multiplicative rather than sequential.

Acknowledgements - This article is the written version of a lecture given at the $18^{\text {th }}$ International Congress of Myriapodology, Budapest, 25-31 August 2019. I am grateful to Zoltán Korsós for his welcome invitation and generous hospitality. Arthur Wallace, Greg Edgecombe and Giuseppe Fusco kindly provided helpful suggestions on the ms. but are not responsible for the idiosyncratic interpretation of myriapod segmentation defended here.

\section{REFERENCES}

Aguinaldo, A.M.A., Turbeville, J.M., Linford, L.S., RIVERA, M.C., GAREY, J.R., RAFF, R.A. \& LAKE, J.A. (1997): Evidence for a clade of nematodes, arthropods and other moulting animals. Nature, 387: 489-493.

doi: $10.1038 / 387489 \mathrm{a} 0$

AKKaRI, N., ENGHOFF, H. \& Minelli, A. (2014): Segmentation of the millipede trunk as suggested by a homeotic mutant with six extra pairs of gonopods. Frontiers in Zoology, 11: 6. doi: $\underline{10.1186 / 1742-9994-11-6}$

ARCHEY, G. (1936): Revision of the Chilopoda of New Zealand. Records of the Auckland Museum, 2: $43-70$.

ARTHuR, W. \& FARROW, M. (1999): The pattern of variation in centipede segment number as an example of developmental constraint in evolution. Journal of Theoretical Biology, 200: 183-191. doi: 10.1006/jtbi.1999.0986

Berto, D. Fusco, G. Minelli, A. (1997): Segmental units and shape control in Chilopoda. Entomologica Scandinavica, Supplement 51: 61-70.

Bonato L., Drago L., Murienne J. (2014): Phylogeny of Geophilomorpha (Chilopoda) inferred from new morphological and molecular evidence. Cladistics, 30: 485-507.

doi: 10.1111/cla.12060

Bonato, L., Foddai, D. \& Minelli, A. (2001): Increase by duplication and loss of invariance of segment number in the centipede Mecistocephalus microporus Haase, 1887 (Chilopoda, Geophilomorpha, Mecistocephalidae). Italian Journal of Zoology, 68: 345-352. doi: $10.1080 / 11250000109356429$

Bonato, L., Foddai, D. \& Minelli, A. (2003): Evolutionary trends and patterns in centipede segment number based on a cladistic analysis of Mecistocephalidae (Chilopoda: Geophilomorpha). Systematic Entomology, 28: 539-579. doi: $\underline{10.1111 / \text { cla. } 12060}$

BrenA, C. (2014): The embryoid development of Strigamia maritima and its bearing on post-embryonic segmentation of geophilomorph centipedes. Frontiers in Zoology, 11: 58. doi: $\underline{10.1186 / \mathrm{s} 12983-014-0058-9}$

BRENA, C. (2015): Myriapoda. In. WANNINGER, A. (ed.) Evolutionary developmental biology of invertebrates, 3: Ecdysozoa I: non-Tetraconata. 
Springer Verlag, Berlin, pp 141-189.

doi: $10.1007 / 978-3-7091-1865-86$

Brena, C. \& AKAM, M. (2012): The embryonic development of the centipede Strigamia maritima. Developmental Biology, 363: 290-307. doi: $\underline{10.1016 / j . y d b i o .2011 .11 .006 ~}$

BRENA, C. \& AKAM, M. (2013): An analysis of segmentation dynamics throughout embryogenesis in the centipede Strigamia maritima. BMC Biology, 11: 112. doi: 10.1186/1741-7007-11-112

Chagas-Júnior, A., Edgecombe, G.D \& Minelli, A. (2008): Variability in trunk segmentation in the centipede order Scolopendromorpha: a remarkable new species of Scolopendropsis Brandt (Chilopoda: Scolopendridae) from Brazil. Zootaxa, 1888: 36-46.

doi: $\underline{10.11646 / \text { zootaxa.1888.1.2 }}$

ChIPMAN, A.D. (2008): Thoughts and speculations on the ancestral arthropod segmentation pathway. In Minelli, A. \& Fusco, G. (eds.). Evolving Pathways: Key Themes in Evolutionary Developmental Biology. Cambridge University Press, Cambridge, pp. 339-355. doi: $10.1017 / \mathrm{CBO} 9780511541582.024$

Chipman, A.D. (2010): Parallel evolution of segmentation by co-option of ancestral gene regulatory networks. BioEssays, 32: 60-70. doi: 10.1002/bies.200900130

ChIPMAN, A.D. (2019): Becoming segmented. In: Fusco, G. (ed.) Perspectives on Evolutionary Developmental Biology. Padova University Press, Padova, pp. 235-244.

Chipman, A.D., Arthur, W. \& AKAM, M. (2004a): A double segment periodicity underlies segment generation in centipede development. Current Biology, 14: 1250-1255. doi: $\underline{10.1016 / \text { j.cub.2004.07.026 }}$

Chipman, A.D., Arthur, W. \& AKam, M. (2004b): Early development and segment formation in the centipede, Strigamia maritima (Geophilomorpha). Evolution \& Development, 6: 78-89. doi: $10.1111 / \mathrm{j} .1525-142 \mathrm{X} .2004 .04016 . \mathrm{x}$

Clark, E., PeEl, A.D. \& AKam, M. (2019): Arthropod segmentation. Development, 146: dev170480. doi: $10.1242 / \mathrm{dev} .170480$

CoOK, O.F. \& LoOMIS, H.F. (1928): Millipeds of the order Colobognatha, with descriptions of six new genera and type species, from Arizona and California. Proceedings of the United States $\mathrm{Na}$ tional Museum, 72: 1-26. doi: $\underline{10.1242 / \mathrm{dev} .170480}$
Couso, J.P. (2009): Segmentation, metamerism and the Cambrian explosion. International Journal of Developmental Biology, 53: 1305-1316. doi: $10.1387 / \mathrm{ijdb} .072425 \mathrm{jc}$

CuVIER, G. (1817 [1816]): Le règne animal distribué d'après son organisation, pour servir de base à l'histoire naturelle des animaux et d'introduction à l'anatomie comparée. Deterville, Paris.

DAMEN, W.G. (2007): Evolutionary conservation and divergence of the segmentation process in arthropods. Developmental Dynamics, 236: 1379-1391. doi: $10.1002 /$ dvdy. 21157

DAMEN, W.G.M., PRPIC N.-M. \& JANSSEN, R. (2009): Embryonic development and the understanding of the adult body plan in myriapods. Soil Organisms, 81: 337-346.

DAVID, J.-F. \& GEOFFROY, J.-J. (2011): Additional molts into 'elongatus' males in laboratory-reared Polydesmus angustus Latzel, 1884 (Diplopoda, Polydesmida, Polydesmidae)_implications for taxonomy. ZooKeys, 156: 41-48. doi: $\underline{10.3897 / \text { zookeys.156.2045 }}$

DAVIS, G.K. \& PATEL, N.H. (1999): The origin and evolution of segmentation. Trends in Genetics, 9: M68-M72. doi: 10.1016/S0168-9525(99)01875-2

DE RoBERTIS, E.M. (2008): The molecular ancestry of segmentation mechanisms. Proceedings of the National Academy of Sciences of the United States of America, 105: 16411-16412. doi: $\underline{10.1073 / \text { pnas.0808774105 }}$

DIRSH, V.M. (1937): Postembryonic growth in the Pachyiulus flavipes C. L. Koch (Diplopoda). Zoologicheskii Zhurnal, 16: 324-335 (in Russian).

Drago, L., Fusco, G. \& Minelli, A. (2008): Nonsystemic metamorphosis in male millipede appendages: long delayed, reversible effect of an early localized positional marker? Frontiers in Zoology, 5: 5. doi: 10.1186/1742-9994-5-5

EdGecombe, G.D. (2011): Chilopoda-Phylogeny. In: MinelLi, A. (ed.) Treatise on Zoology - Anatomy, Taxonomy, Biology. The Myriapoda, Volume 1, Brill, Leiden, pp. 339-354. doi: $\underline{10.1163 / 9789004188266 \_018}$

Edgecombe, G.D. (2015): Diplopoda-Phylogenetic relationships. In: MinELl, A. (ed.) Treatise on Zoology - Anatomy, Taxonomy, Biology. The Myriapoda, Volume 2, Brill, Leiden, pp. 353362. doi: $10.1163 / 9789004188273016$

EERnisse, D.J., Albert J.S. \& ANDERSON F.E. (1992): Annelida and Arthropoda are not sister 
taxa: a phylogenetic analysis of spiralian Metazoan phylogeny. Systematic Biology, 41: 305330. doi: $10.1093 /$ sysbio/41.3.305

ENGHOFF, H. (1990): The ground-plan of chilognathan millipedes (external morphology). In: A. MinelLI (ed.) Proceedings of the $7^{\text {th }}$ International Congress of Myriapodology. E. J. Brill, Leiden, pp. $1-21$.

ENGHOFF, H. (2011): Trans-segmental serial colour patterns in millipedes and their developmental interpretation (Diplopoda). International Journal of Myriapodology, 6: 1-27. doi: $10.3897 /$ ijm.6.1949

Enghoff, H., Dohle, W. \& Blower, J.G. (1993): Anamorphosis in millipedes (Diplopoda) - the present state of knowledge with some developmental and phylogenetic considerations. Zoological Journal of the Linnean Society, 109: 103-234. doi: 10.1111/j.1096-3642.1993.tb00305.x

Enghoff, H., Golovatch, S., Short, M., Stoev, P. \& WeSEnER,T. (2015): Diplopoda-Taxonomic overview. In: Minelli, A. (ed.) Treatise on Zoology - Anatomy, Taxonomy, Biology. The Myriapoda, Volume 2, Brill, Leiden, pp. 363-453. doi: $\underline{10.1163 / 9789004188273 \quad 017}$

FABRE, J.-H. (1855): Recherches sur l'anatomie des organes reproducteurs et sur le développement des myriapodes. Annales de Sciences Naturelles (Zoologie), 3: 256-320.

Fernández, R., Edgecombe, G.D. \& Giribet, G. (2016): Exploring phylogenetic relationships within Myriapoda and the effects of matrix composition and occupancy on phylogenomic reconstruction. Systematic Biology, 65: 871-889. doi: 10.1093/sysbio/syw041

FuscO, G. (2005): Trunk segment numbers and sequential segmentation in myriapods. Evolution \& Development, 7: 608-617. doi: 10.1111/j.1525142X.2005.05064.X

Fusco, G. \& Minelli, A. (2013): Arthropod segmentation and tagmosis. In Minelli, A., BoXshall, G. \& Fusco, G. (eds.) Arthropod Biology and Evolution. Molecules, Development, Morphology. Springer, Heidelberg, pp. 197-221. doi: 10.1007/978-3-662-45798-6_9

GREen, J. \& AKAM, M. (2013). Evolution of the pair rule gene network: insights from a centipede. $D e$ velopmental Biology, 382: 235-245. doi: $\underline{10.1016 / j . y d b i o .2013 .06 .017}$
HANNIBAL, R.L. \& PATEL, N.H. (2013): What is a segment? EvoDevo, 4(1): 35. doi: 10.1186/20419139-4-35

HAyden, L., PARKes, G. \& Arthur, W. (2012): Segment number, body length, and latitude in geophilomorph centipedes: a 'converse-Bergmann' pattern. Biological Journal of the Linnean Society, 107: 166-174. doi: 10.1111/j.10958312.2012.01914.x

Horneland, E.O. \& MEIDELl, B.A. (1986): The epimorphosis of Strigamia maritima (Leach, 1817) (Chilopoda: Geophilidae). Insect Systematics \& Evolution, 17: 127-129. doi: $\underline{10.1163 / 187631286 \times 00161}$

Hughes, C.L. \& Kaufman, T. C. (2002). Exploring myriapod segmentation: the expression patterns of even-skipped, engrailed, and wingless in a centipede. Developmental Biology, 247: 47-61. doi: 10.1006/dbio.2002.0683

JANSSEN, R. (2012): Segment polarity gene expression in a myriapod reveals conserved and diverged aspects of early head patterning in arthropods. Development Genes and Evolution, 222: 299-309. doi: 10.1007/s00427-012-0413-9

Janssen, R., Budd, G.E., PrPic, N.M. \& Damen, W.G.M. (2011): Expression of myriapod pair rule gene orthologs. EvoDevo, 2: 5. doi: $10.1186 / 2041-9139-2-5$

JANSSEN, R., DAMEN, W.G.M. \& BuDD, G.E. (2012): Expression of pair rule gene orthologs in the blastoderm of a myriapod: evidence for pair rulelike mechanisms? BMC Developmental Biology, 12: 15 . doi: $10.1186 / 1471-213 X-12-15$

Janssen, R., Le Gouar, M., Pechmann, M., Poulin, F., Bolognesi, R., SCHWAGer, E.E., Hopfen, C., Colbourne, J.K., Budd, G.E., Brown, S.J., PrPiC, N.-M., Kosiol, C., Vervoort, M., Damen, W.G.M., Balavoine, G. \& MCGREgor, A.P. (2010): Conservation, loss, and redeployment of Wnt ligands in protostomes: implications for understanding the evolution of segment formation. BMC Evolutionary Biology, 10: 374. doi: $\underline{10.1186 / 1471-2148-10-374}$

JANSSEN, R., PRPIC, N.M. \& DAMEN, W.G.M. (2004): Gene expression suggests decoupled dorsal and ventral segmentation in the millipede Glomeris marginata (Myriapoda: Diplopoda). Developmental Biology, 268: 89-104. doi: $10.1016 /$ j.ydbio.2003.12.021 
JANSSEN, R., PRPIC, N.M. \& DAMEN, W.G.M. (2006a): Dorso-ventral differences in gene expression in Glomeris marginata (Villers, 1789) (Myriapoda: Diplopoda). Norwegian Journal of Entomology, 53: 129-137.

JANSSEN, R., PRPIC, N.M. \& DAMEN, W.G.M. (2006b): A review of the correlation of tergites, sternites, and leg pairs in diplopods. Frontiers in Zoology, 3: 2. doi: 10.1186/1742-9994-3-2

KeTtLe, C. \& ARTHUR, W. (2000): Latitudinal cline in segment number in an arthropod species, Strigamia maritima. Proceedings of the Royal Society of London B Biological Sciences, 267: 13931397. doi: $10.1098 / \mathrm{rspb} .2000 .1155$

Kettle, C., Johnstone, J., Jowett, T., Arthur, H. \& ARTHUR, W. (2003): The pattern of segment formation, as revealed by engrailed expression, in a centipede with a variable number of segments. Evolution \& Development, 5: 198-207. doi: 10.1046/j.1525-142X.2003.03027.x

LAWRENCE, R.F. (1963): New Myriapoda from Southern Africa. Annals of the Natal Museum, 15: 297-318

LeŚniewsKa, M., Bonato, L., Minelli, A. \& FusCo, G. (2009): Trunk anomalies in the centipede Stigmatogaster subterranea provide insight into late-embryonic segmentation. Arthropod Structure \& Development, 38: 417-426. doi: $\underline{10.1016 / j . a s d .2009 .05 .001}$

MAYNARD SMith, J. (1960): Continuous, quantized and modal variation. Proceedings of the Royal Society of London, B 152: 397-409. doi: $10.1098 / \mathrm{rspb} .1960 .0047$

Minelli, A. (1985): Post-embryonic development and the phylogeny of geophilomorph centipedes (Chilopoda). Bijdragen tot de Dierkunde, 55: 143-148.

Minelli, A. (2000): Holomeric vs meromeric segmentation: a tale of centipedes, leeches, and rhombomeres. Evolution \& Development, 2: 3548. doi: 10.1046/j.1525-142x.2000.00030.x

MinelLi, A. (2001): A three-phase model of arthropod segmentation. Development Genes and Evolution, 211: 509-521. doi: 10.1007/s004270100180

Minelli, A. (2003): The Development of Animal Form. Cambridge University Press, Cambridge. doi: $10.1007 / \mathrm{s} 004270100180$

Minelli, A. \& Bortoletto, S. (1988): Myriapod metamerism and arthropod segmentation. Bio logical Journal of the Linnean Society, 33: 323343. doi: 10.1111/j.1095-8312.1988.tb00448.x

Minelli, A., Brena, C., Deflorian, G., Maruzzo, D. \& FusCO, G. (2006): From embryo to adult. Beyond the conventional periodization of arthropod development. Development Genes and Evolution, 216: 373-383. doi: 10.1007/s00427-006$\underline{0075-6}$

Minelli, A., Chagas-Júnior, A. \& Edgecombe, G.D. (2009): Saltational evolution of trunk segment number in centipedes. Evolution \& Development, 11: 318-322. doi: 10.1111/j.1525142X.2009.00334.X

Minelli, A., Foddai, D., Pereira, L.A. \& Lewis, J.G.E. (2000): The evolution of segmentation of centipede trunk and appendages. Journal of Zoological Systematics and Evolutionary Research, 38:103-117. doi: 10.1046/j.1439$\underline{0469.2000 .382137 . x}$

MinelLi, A. \& Fusco, G. (2004): Evo-devo perspectives on segmentation: model organisms and beyond. Trends in Ecology and Evolution, 19: 423429. doi: 10.1016/j.tree.2004.06.007

Minelli, A. \& Fusco, G. (2013): Arthropod postembryonic development. In. Minelli, A., Boxshall, G. \& FusCO, G. (eds.) Arthropod Biology and Evolution. Molecules, Development, Morphology. Springer, Heidelberg, pp. 91-122. doi: $\underline{10.1007 / 978-3-662-45798-6 ~} 5$

Minelli, A., Maruzzo, D. \& Fusco, G. (2010): Multi-scale relationships between numbers and size in the evolution of arthropod body features. Arthropod Structure \& Development, 39: 468477. doi: $10.1016 / \mathrm{j}$. asd.2010.06.002

Minelli, A., Pasqual, C. \& Etonti, G. (1984): I Chilopodi Geofilomorfi del gen. Himantarium C.L. Koch con particolare riferimento alle popolazioni italiane. Società veneziana di Scienze naturali, Lavori, 9: 73-84.

Misioch, M. (1978): Variation of characters in some geophilid chilopods. Abhandlungen und Verhandlungen des naturwissenschaftlichen Vereins in Hamburg, 21/22: 55-62.

NGUYEN DUY-JACQUEMIN, M. (1972): Régénération antennaire chez les larves et les adultes de Polyxenus lagurus (Diplopode, Penicillate). Comptes rendus hebdomadaires des Séances de l'Académie des Sciences, Série D, Sciences Naturelles, 274: 1323-1326. 
NÜSSlein-VolhaRd, C. \& Wieschaus, E. (1980): Mutations affecting segment number and polarity. Nature, 287: 795-801. doi: $\underline{10.1038 / 287795 a 0}$

PEEL, A. (2004): The evolution of arthropod segmentation mechanisms. Bioessays, 26: 1108-1116. doi: 10.1002/bies.20097

Peel, A., Chipman, A.D. \& AKam, M. (2005): Arthropod segmentation: beyond the Drosophila paradigm. Nature Reviews Genetics, 6: 905-916. doi: $\underline{10.1038 / \mathrm{nrg} 1724}$

PETIT, G. (1973): Étude morphologique de la régénération des appendices ambulatoires chez le diplopode Polydesmus angustus Latz. Bulletin de la Société zoologique de France, 98: 43-53.

PeTiT, G. (1974): Sur les modalités de la croissance et la régenération des antennes de larves de Polydesmus angustus Latzel. Symposia of the Zoological Society of London, 32: 301-315.

Prunescu, C. \& CAPuse, I. (1971): Nouvelles données sur le début du développment postembryonnaire chez les myriopodes de l'ordre Geophilomorpha. Travaux du Muséum national d'histoire naturelle "Grigore Antipa", 11: 111119.

SANDER, K. (1976): Specification of the basic body pattern in insect embryogenesis. Advances in Insect Physiology, 12: 125-238. doi: $10.1016 / \mathrm{S} 0065-2806(08) 60255-6$

SAUNDERS, P.T. \& Ho, M.V. (1984): The complexity of organisms. In POLLARD, J.W. (ed.) Evolutionary Theory: Paths into the Future. Wiley, Chichester, pp. 121-139.

SCHILEYKO, A. (2006): Redescription of Scolopendropsis bahiensis (Brandt, 1841), the relations between Scolopendropsis and Rhoda, and notes on some characters used in scolopendromorph taxonomy (Chilopoda: Scolopendromorpha). Arthropoda Selecta, 15: 9-17.

SEAVER, E.C. (2003): Segmentation: mono- or polyphyletic? International Journal of Developmental Biology, 47: 583-595.

Shear, W.A. \& Edgecombe, G.D. (2010): The geological record and phylogeny of Myriapoda. Arthropod Structure \& Development, 39: 174-190. doi: $10.1016 /$ j.asd.2009.11.002
SHEAR, W.A., FERrEIRA, R.L., INIESTA, L.F.M. \& MAREK, P. (2016): A millipede missing link: Dobrodesmidae, a remarkable new polydesmidan millipede family from Brazil with supernumerary rings (Diplopoda, Polydesmida), and the establishment of a new suborder Dobrodesmidea. Zootaxa, 4178: 371-390.

doi: $\underline{10.11646 / \text { zootaxa.4178.3.4 }}$

Shelley, R. (1975): The identity of Nannaria conservata Chamberlin, with notes on an abnormal male and descriptions of two new species of Nannaria from North Carolina (Diplopoda: Polydesmida: Xystodesmidae). Proceedings of the Biological Society of Washington, 88: 179-187.

TAuTZ, D. (2004): Segmentation. Developmental Cell, 7: 301-312. doi: 10.1016/j.devcel.2004.08.008

Uliana, M., Bonato, L. \& Minelli, A. (2007): The Mecistocephalidae of the Japanese and Taiwanese islands (Chilopoda: Geophilomorpha). Zootaxa, 1396: 1-84. doi: 10.11646/zootaxa.1396.1.1

Vedel, V., Apostolou, Z., Arthur, A., AKam, M. \& BRENA, C. (2010). An early temperature-sensitive period for the plasticity of segment number in the centipede Strigamia maritima. Evolution \& Development, 12: 347-352. doi: 10.1111/j.1525142X.2010.00421.x

Vedel, V., BRENA, C. \& ARThuR, W. (2009): Demonstration of a heritable component of the variation in segment number in the centipede Strigamia maritima. Evolution \& Development, 11: 434-440. doi: $\underline{10.1111 / \mathrm{j} .1525-142 X .2010 .00421 . \mathrm{X}}$

Vedel, V., Chipman, A.D., AKam, M. \& Arthur, W. (2008): Temperature-dependent plasticity of segment number in an arthropod species: the centipede Strigamia maritima. Evolution \& Development, 10: 487-492.

doi: $\underline{10.1111 / \mathrm{j} .1525-142 X .2008 .00259 . \mathrm{X}}$

VERHOEFF, K.W. (1916): Abhängigkeit der Diplopoden und besonders der Juliden-Schaltmännchen von äußeren Einflüssen. Zeitschrift für wissenschaftliche Zoologie, 116: 535-586.

VERHOEFF, K.W. (1928): Durch Zucht erhaltene Formen des Polydesmus complanatus, illyricus Verh. und ihre Bedeutung, sowie Beurteilung der Elongation. Zeitschrift für Morphologie und Ökologie der Tiere, 12: 684-705. doi: 10.1007/BF00403123 